the triple positivity was significantly associated with male gender $(\mathrm{OR}=3.5$; $p=0.02)$, the presence of rheumatoid nodules $(O R=5,3 ; p=0.015)$ and pulmonary involvement ( $\mathrm{OR}=2.6 ; \mathrm{p}=0.007)$. Anti-IFI16 auto-Abs were associated to male gender independently of the presence of the other two auto-Abs.

Conclusions: Our study demonstrated that anti-CEP-1 auto-Abs may participate to the development of RA-associated pulmonary manifestation together with anti-CCP and that the assessment of multiple auto-Abs in daily practice may help clinician to stratify RA patients at identify those at higher risk to develop extra-articular manifestations.

References:

[1] Alunno A et al. Arthritis Care Res (Hoboken) 2016;68(4):440-5.

[2] Montes A et al. Arthritis Rheum 2012;64(10):3102-3110.

Disclosure of Interest: None declared

DOI: 10.1136/annrheumdis-2017-eular.3564

\section{AB0192 SERUM MEASURES OF TYPE I COLLAGEN DEGRADATION ARE SURROGATE MARKERS OF JOINT DESTRUCTION AND PROGRESSION; FIRST STEPS TOWARDS A PROGNOSTIC SCORE}

A.C. Bay-Jensen ${ }^{1}$, C. Bager ${ }^{2}$, A.S. Siebuhr ${ }^{1}$, H. Bay Nielsen ${ }^{2}$, M.A. Karsdal ${ }^{1}$. ${ }^{1}$ Rheumatology, Nordic Bioscience Biomarkers and Research; ${ }^{2}$ Proscion. Herlev, Denmark

Background: Monitoring of patients with rheumatoid arthritis (RA) requires assessment of biomarkers reflecting disease activity and its progression. There is a need for non-invasive markers for frequent monitoring of disease severity and progression as well as response to therapy.

Objectives: Serological markers together with clinical parameters was tested in a multi-marker model to assess its ability to objectively predict progression of RA. Methods: Current post-hoc analysis included RA patients from the biomarker substudy of the phase III clinical study LITHE investigating the safety and efficacy of tocilizumab ${ }^{1-4}$. Patients had moderate/severe, active RA. In addition, only patients of the placebo arm and with total sharp score (SHP) recorded at baseline (BL), week 24 (W24) and W52 were included. Progressors were defined as the delta from BL to W24 and W24 to W52. Biochemical markers reflecting tissue turnover (table) were assessed at $\mathrm{BL}$ and $\mathrm{W} 16$. Associations with structural progression (deltaSHP) were investigated by spearman's $r$, least squared multivariate and logistic regression. Covariates were CRP, sex, BMI, age, disease duration, DAS-ESR, no. prior DMARDs/aTNF use and SHP/BL. The data were divided into a training and confirmation set; 1 ) association between markers/W16 and deltaSHP/W52 ( $\mathrm{n}=31$ prog./42 non-prog.), 2) association between markers/BL and deltaSHP/W24 ( $n=33 / 48)$.

Results: The training set. Eight markers were correlated $(R>0.2)$ with deltaSHP/W52. Of these C1M, PINP, ICTP and MMP3 were predictive for of progression (deltaSHP/W52>0) with ORs of 3.2 [1.3-8.0], 4.0 [1.4-12], 8.5 [2.4-31], and 2.5 [1.3-5.1]; all $p<0.01$, respectively. A logistic model for prediction of disease progression incorporating C1M, ICTP, disease duration and BMI demonstrated an AUC of $0.77[0.66-0.86], p<0.01$. The model correctly identified $72 \%$ of the progressors. textitThe confirmation set: The results were confirmed in the second dataset with an AUC of $0.75[0.64-0.81], p<0.01$. The model correctly identified $65 \%$ of the progressors.

\begin{tabular}{|c|c|c|c|}
\hline Biochemical marker & Description & Biomarker of & $\begin{array}{l}\text { Spearman correlation } \\
\text { between DeltaSHP/W52 and } \\
\text { baseline biochemical marker } \\
\text { R>0.2 }\end{array}$ \\
\hline C1M & $\begin{array}{l}\text { MMP-mediated type I } \\
\text { collagen degradation }\end{array}$ & Connective tissue destruction & 0.377 \\
\hline C2M & $\begin{array}{l}\text { MMP-mediated type II } \\
\text { collagen degradation }\end{array}$ & Cartilage degradation & 0.088 \\
\hline C3M & $\begin{array}{l}\text { MMP-mediated type III } \\
\text { collagen degradation }\end{array}$ & Connective tissue destruction & 0.277 \\
\hline CAM & $\begin{array}{l}\text { MMP-mediated type IV } \\
\text { collagen degradation }\end{array}$ & $\begin{array}{l}\text { Basement membrane } \\
\text { destruction }\end{array}$ & 0.157 \\
\hline C6M & $\begin{array}{l}\text { MMP-mediated type VI } \\
\text { collagen degradation }\end{array}$ & Connective tissue destruction & 0.175 \\
\hline CRP & C-reactive protein & Acute reactant & 0.354 \\
\hline CRPM & C-reactive degradation & Tissue inflammation & 0.290 \\
\hline $\mathrm{CTX}-1 / \mathrm{OC}$ & $\begin{array}{l}\text { Ratio between cathepsin K- } \\
\text { mediated type I collagen } \\
\text { degradation and osteocalcin }\end{array}$ & $\begin{array}{l}\text { Bone turnover balance (Bone } \\
\text { resporption/formation) }\end{array}$ & 0.063 \\
\hline Gender & . & - & 0.090 \\
\hline HAQ & $\begin{array}{l}\text { Health assessment } \\
\text { questionnaire }\end{array}$ & & -0.032 \\
\hline ICTP & $\begin{array}{l}\text { MMP-mediated type I } \\
\text { collagen degradation }\end{array}$ & $\begin{array}{l}\text { Connective tissue destruction } \\
\text { /bone degradation }\end{array}$ & 0.334 \\
\hline MMP3 & Matrix metalloproteinase 3 & Joint inflammation & 0.226 \\
\hline Pain (VAS) & 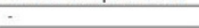 & 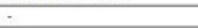 & 0.073 \\
\hline Patient global score (VAS) & - & - & 0.110 \\
\hline Physician global score (VAS) & - & $\cdot$ & 0.051 \\
\hline PIIANP & Propeptide of type ll collagen & Cartilage formation & -0.077 \\
\hline PINP & Propeptide of type I collagen & $\begin{array}{l}\text { Connective tissue and bone } \\
\text { formation }\end{array}$ & 0.217 \\
\hline VCAM & $\begin{array}{l}\text { MMP-mediated Versican } \\
\text { degradation }\end{array}$ & Epithelial turnover & -0.054 \\
\hline VICM & $\begin{array}{l}\text { MMP-mediated degradation } \\
\text { of citrullinated vimentin }\end{array}$ & Macrophage activity & 0.232 \\
\hline
\end{tabular}

Conclusions: We demonstrated that a multi-marker model was able to pint-point, which patients were more likely to be structural progressors. Such first steps to build a progression model, rather than a score reflecting disease activity only, may enrich clinical studies with structurally active diseaese. Importantly, the markers with strongest influence were those associated with MMP-driven bone (ICTP) and connective tissue $(\mathrm{C} 1 \mathrm{M})$ remodelling.

\section{References:}

[1] Smolen JS.Tocilizumab inhibits progression of joint damage in rheumatoid arthritis irrespective of its anti-inflammatory effects: disassociation of the link between inflammation and destruction. Ann Rheum Dis 2012.

[2] Kremer JM. Tocilizumab inhibits structural joint damage in rheumatoid arthritis patients with inadequate responses to methotrexate: results from the doubleblind treatment phase of a randomized placebo-controlled trial of tocilizumab safety and prevention of structu. Arthritis Rheum 2011.

[3] Bay-Jensen AC. Effect of tocilizumab combined with methotrexate on circulating biomarkers of synovium, cartilage, and bone in the LITHE study. Semin Arthritis Rheum 2014.

[4] Bay-Jensen AC. Early changes in blood-based joint tissue destruction biomarkers are predictive of response to tocilizumab in the LITHE study.Arthritis Res Ther 2016.

Disclosure of Interest: A. Bay-Jensen Shareholder of: Nordic Bioscience, Employee of: Nordic Bioscience, C. Bager Employee of: Proscion, A. S. Siebuhr Employee of: Nordic Bioscience, H. Bay Nielsen Employee of: Proscion, M. Karsdal Shareholder of: Nordic Bioscience, Employee of: Nordic Bioscience DOI: 10.1136/annrheumdis-2017-eular.6676

\section{AB0193 MEDICAL ADHERENCE IN PATIENTS WITH TIGHTLY CONTROLLED RHEUMATOID ARTHRITIS}

A. Caliskan Uckun, F.G. Yurdakul, H. Bodur. Physical Medicine and Rehabilitation, Ankara Numune Research and Education Hospital, Ankara, Turkey

Background: Medication adherence is very important in the treatment of rheumatoid arthritis (RA). However, medication adherence of the patients with RA was not optimal in many of the studies (1-2).

Objectives: The purpose of this study was to investigate the medication adherence in tightly controlled RA patients and reasons of non-adherence.

Methods: A total of 82 RA patients (65 women and 17 men) who followed regularly in our outpatient clinic were included. Socio-demographic features and medical history were collected. The eight-item Morisky scale (MMAS-8) was used to evaluate adherence to medication. Disease activity score (DAS28), health assessment questionnaire (HAQ), mini mental state examination (MMSE) test and Beck depression inventory (BDI) were evaluated.

Results: According to Morisky scale, $34.1 \%, 15.9 \%$ and $50 \%$ of our patients were categorized as low, moderate and high adherence, respectively. The most prevalent noticed barriers for adherence were forgetting medication, inadequate information about using instructions, side effects of medications (Table 1). Socio demographic features, duration of disease, type and number of drugs used per day, the route of drug administration, co-morbid diseases, body mass index, smoking and alcohol consumption were not found to be associated with medication adherence, whereas low MMSE and high BDI score were associated with low medication adherence $(p=0.009$ and $p=0.011$, respectively). We found that the disease activity was significantly higher in non-adherent cases $(p=0.00)$ (Table 2).

Table 1. Barriers to medication adherence

\begin{tabular}{|c|c|c|c|c|}
\hline Barriers & $\%$ & & & \\
\hline Forgetfulness & $41.4 \%$ & & & \\
\hline Inadequate information & $22 \%$ & & & \\
\hline Side effects of medications & $17 \%$ & & & \\
\hline Fears about drug benefit & $12.2 \%$ & & & \\
\hline Anxiety about side effects & $4.8 \%$ & & & \\
\hline Cost of medications & $2.6 \%$ & & & \\
\hline \multicolumn{5}{|c|}{ Table 2. Medication adherence and disease activity } \\
\hline DAS 28 & $\begin{array}{c}\text { Low adherence } \\
\text { (Morisky <6) }\end{array}$ & $\begin{array}{l}\text { Moderate adherence } \\
\quad \text { (Morisky 6-7) }\end{array}$ & $\begin{array}{l}\text { High adherence } \\
(\text { Morisky = 8) }\end{array}$ & Total \\
\hline Remission $(<2.6)$ & $2(5.6 \%)$ & $5(13.9 \%)$ & $29(80.6 \%)$ & 36 \\
\hline Low disease activity $(2.6-<3.2)$ & $7(36.8 \%)$ & $3(15.8 \%)$ & $9(47.4 \%)$ & 19 \\
\hline \multicolumn{5}{|l|}{ Moderate disease activity } \\
\hline$(3.2-<5.1)$ & $17(68.0 \%)$ & $5(20 \%)$ & $3(12 \%)$ & 25 \\
\hline High disease activity $(\geq 5.1)$ & $2(100 \%)$ & $0(0 \%)$ & $0(0 \%)$ & 2 \\
\hline Total & 28 & 13 & 41 & 82 \\
\hline
\end{tabular}

DAS: Disease activity score.

Conclusions: Our RA patients who were closely followed had 50\% high medication adherence. This rate is quite high compared to other studies using MMAS-8. It should be kept in mind that tight control and adequate communication increase medication adherence but different parameters may also be effective. Assessing cognitive disorders and emotional problems of the patient will be beneficial for improving adherence and controlling disease activity.

References:

[1] Gadallah MA, Boulos DN, Gebrel A, Dewedar S, Morisky DE. Assessment of rheumatoid arthritis patients' adherence to treatment. Am J Med Sci. 2015;349:151-6.

[2] Ferguson A, Ibrahim FA, Thomas V, Weinman J, Simpson C, Cope AP, Scott 
DL, Lempp H. Improving medication adherence in rheumatoid arthritis (RA): a pilot study. Psychol Health Med. 2015;20(7):781-9.

Disclosure of Interest: None declared

DOI: 10.1136/annrheumdis-2017-eular.2837

\section{AB0194 JOURNEY OF A PATIENT WITH RHEUMATOID ARTHRITIS: DELAY IN DIAGNOSIS AND TREATMENT}

A. Luissi, J.E. Rosa, F. Vergara, F.S. Pierini, M. Scolnik, M.V. Garcia, E.R. Soriano. Rheumatology section, Medical Services, Hospital Italiano de Buenos Aires, Buenos Aires, Argentina

Background: It has been shown that there is a window of opportunity for treatment in Rheumatoid Arthritis (RA). Several Argentinean studies showed an average of 8 months to arrive to a rheumatology visit and 12 months to receive DMARDs. There aren't recent studies.

Objectives: To establish delay time from onset of rheumatoid arthritis (RA) symptoms to the first rheumatology visit, to diagnosis of the disease and to the beginning of treatment with DMARDs; and to assess impact of such delay on structural damage, in a cohort of RA patients.

Methods: A retrospective study was performed including all patients with RA (fulfilling ACR/EULAR 2010 criteria) seen at a Prepaid Medical Health Plan between 2002-2015. Diagnosis delay and its impact on functional capacity measured by HAQ-A and structural damage by Sharp van der Hejde score (SvdH) was estimated. Demographic and clinical data, and dates ofdiagnosis, onset of symptoms and HAQ-A were extracted from electronic medical records. Svdh score was performed by an experienced rheumatologist.

Results: 246 patients (mean age at diagnosis 67.25 \pm 14 years, 199 (81\%) female) were included. Clinical presentation was poliarticularin $49 \%$ of the cases, oligoarticularin $47 \%$ and monoarticular in 3\%. $79 \%$ had high titers of anti-cyclic citrullinated peptide antibodies, $12 \%$ low titers, and $9 \%$ were negative. Rheumatoid factor was positive in $82.5 \%$. Mean time of follow up was 7 years (SD: 3.8 ). At the end of the follow-up, median HAQ-A $(n=145)$ was 0.125 (IRQ: $0-0.87)$. Hands and feet lastxray available were analized in 171 patients. Median Svdh score was 15 (IQR: 6-33). 242 patients (98.4\%) received DMARDs as initial treatment: methotrexate monotherapy (76\%) was the most frequent one. 41 patients (17\%) received biological agents at some point of their disease. Table 1 shows different delay times in accessing rheumatology consultation, diagnosis and beginning of treatment.

At the end of follow up, 21 patients (12.28\%) had noradiological damage (Svdh score $=0$ ). In the ROC curve (AUC $0.57,95 \% \mathrm{Cl}: 0.45-0.69$ ), 5.6 months of diagnosis delay was the best cut off valueto discriminate the presence of erosions (SvdH erosions score $>0$ ), with a sensitivity and specificity of $54.17 \%$ and $61.90 \%$, respectively. Delay in diagnosis greater than 12 months $(n=70)$ was associated with significantly radiological damage: Svdh mean 30.91 (IC 95\% 21.99-39.79) vs 21.32 (IC 95\% 16.93-25.72); $p=0.0325$.

Table 1. different delay times

\begin{tabular}{lcc}
\hline Variable & Mean (SD) & Median (IQR) \\
\hline Time from first symptoms to first rheumatology visit (months) & $9.21(20.50)$ & $3(1-7)$ \\
Time from first symptoms to diagnosis (months) & $14.2(24)$ & $4.8(2.4-13)$ \\
Time fromfirst symptoms to DMARDs indication (months) & $16.9(25.4)$ & $7(3-17)$ \\
Time from first symptoms to biological indication (years) & $6.2(4.8)$ & $5.7(2.4-7.2)$ \\
\hline
\end{tabular}

Conclusions: In a Prepaid Medical Health Planwith ease of referral, there is still a significant delay in diagnosis and treatment of RA patients.Delay in diagnosis greater than 12 months was associated with more radiological damage.

Disclosure of Interest: None declared

DOI: 10.1136/annrheumdis-2017-eular.2967

\section{AB0195 IS THERE AN ASSOCIATION BETWEEN PERIODONTITIS AND LEVELS OF ANTI-CITRULLINATED PEPTIDES ANTIBODIES IN RHEUMATOID ARTHRITIS?}

B. Rodríguez-Lozano ${ }^{1}$, J. González Febles ${ }^{2}$, F. Sánchez Alonso ${ }^{3}$, J.L. Garnier Rodríguez $^{4}$, S. Dadlani ${ }^{4}$, Y. Barrios ${ }^{5}$, M. Sanz Alonso ${ }^{6}$, F. Díaz González ${ }^{1}$. ${ }^{1}$ Rheumatology, Hospital Universitario de Canarias, Tenerife, ${ }^{2}$ Periodontology, UCM, Madrid; ${ }^{3}$ Research Unit, Sociedad Española de Reumatología, Madrid;

${ }^{4}$ Odontology/Periodontology, Dental Clinic Dr Garnier, S/C Tenerife;

5 Immunology Unit. Central Laboratory, Hospital Universitario de Canarias, Tenerife; ${ }^{6}$ Periodontology, UCM, Madrid, Spain

Background: Positivity of anti-citrullinated peptides antibodies (ACPA) indicates severity in Rheumatoid Arthritis (RA). There is evidence for chronic periodontitis (PD) in RA autoimmune response by periodontopathogenic bacteria such as P.gingivalis, through citrullination of $\mathrm{L}$-arginine.

Objectives: 1.To determine whether there is an association between PD and its severity with $\mathrm{ACPA}(+)$.2.To assess relationship between PD and ACPA titres.3.To identify association between certain periodontal parameters and ACPA titres and their possible cutoff points.

Methods: Observational, cross-sectional study RA patients $>18$ with $>4$ teeth, no tooth cleaning, antibiotic intake 6 months before.Socio-demographic and anthropometric variables, annual dental prophylaxis and comorbidities.Serum
ACPA detection:Ab lgG against CCP2 (ELISA)Eurodiagnostica:positive $>25$; ACPA titres stratification:Low (25-75), moderate (76-300) and high $(>300)$. Periodontal parameters: plaque index ( $\mathrm{PI})$, bleeding on probing (Bop), probing pocket depth,clinical attachment level (CAL). CAL loss was categorized according to European Workshop 2005 (Tonetti):T level0 (absence), TL1 (mild), TL2 (severe). Statistical analysis:t-student, Kruskal Wallis, Chi- squared tests by Stata program 13.1.

Results: 187 RA patients included (table 1),ACPA determined in 168 patients: $67.86 \%(+)$ with similar titres distribution: low $18 \%$, moderate $26 \%$, high $23 \%$. PD:182 patients (97.3\%):TL1 52.4\%,TL2 44.9\%. Although prevalence of severe $\mathrm{PD} / \mathrm{ACPA}(+)$ was higher compared to PD/ACPA(-) $(69.2 \%$ vs $30.7 \%)$, there was no association between PD and ACPA positivity/titres. Regarding the association with periodontal parameters, there was tendency of association between ACPA $(+)$ and number of periodontal pockets $\geq 5 \mathrm{~mm}$ (NPP), OR $1.02(95 \% \mathrm{Cl} 0.9-1.04)$ adjusted. There was a gradient effect, where NPP increased as ACPA titles increased, which was significant for high ACPA titres $(p \leq 0.05$,OR $1.0395 \% \mathrm{Cl}$ $1.0-1.05)$. When $\mathrm{ACPA}(+)$ was related to $\% \mathrm{PI}$ and $\mathrm{BoP}$, a strong association was observed for $\mathrm{PI}, \mathrm{OR} 10.32(\mathrm{p}<0,026)$, and only a tendency for BoP $(\mathrm{p}<0.062)$. With cutoff points of $8 \% \mathrm{PI}$ and $65 \% \mathrm{BoP}$, a risk for $\mathrm{ACPA}(+)$ was detected with an OR 2.19 and OR 2.45, respectively.

Table 1

\begin{tabular}{lcc}
\hline & $\mathrm{RA}(\mathrm{N})$ & $\mathrm{RA}(\%)$ \\
\hline Female sex & 147 & 78.6 \\
Mean age (SD) & $54.4(10.8)$ & \\
Follow up time, median (SD), years & $8.88(7.32)$ & \\
Early RA & 35 & 18.7 \\
Rheumatoid factor, seropositive & 138 & 74.2 \\
Disease Activity Ranges & & \\
$\quad$ Remission & 39 & 20.9 \\
$\quad$ Low & 45 & 24.1 \\
Moderate & 85 & 45.4 \\
$\quad$ High & 18 & 9.6 \\
Medication RA & & \\
$\quad$ Without Treatment & 10 & 5.3 \\
$\quad$ DMARDs & 99 & 52.9 \\
22 DMARDs & 22 & 11.8 \\
Biologic Drugs & 56 & 29.9 \\
\hline
\end{tabular}

Conclusions: 1 .Despite higher prevalence of severe PD in $A C P A(+)$ patients, we found no association between the presence of PD and ACPA positivity nor with serum titres. 2. On analysis of ACPA titres in relation to the severity of the periodontal parameters, there was a "gradient" risk, where NPP increased as ACPA titres increased, which was significant for high ACPA titres.3. Risk cutoff points for $\mathrm{ACPA}(+)$ were $8 \%$ for $\mathrm{PI}$ and $65 \%$ for BoP.

Disclosure of Interest: None declared

DOI: 10.1136/annrheumdis-2017-eular.4420

\section{AB0196 VASCULAR ENDOTHELIAL GROWTH FACTOR IN PATIENTS WITH RHEUMATOID ARTHRITIS}

B. Rebrov ${ }^{1}$, E. Komarova ${ }^{1}$, A. Blagodarenko ${ }^{1}$, G. Belkina ${ }^{2}$, I. Pokryshka ${ }^{3}$. ${ }^{1}$ Internal Medcine; ${ }^{2}$ Medical Chemistry, SI "Lugansk State Medical University";

${ }^{3}$ Rheumatology, Lugansk Clinical Regional Hospital, Lugansk, Ukraine

Background: The level of vascular endothelial growth factor (VEGF) may reflect the intensity of angiogenesis, which is an important step in the initiation and development of chronic rheumatoid arthritis (RA).

Objectives: to study features of VEGF level changes in the blood of RA patients, depending on the duration of the disease, the degree of activity, the level of antibodies to cyclic citrullinated peptide (anti-CCP)

Methods: 194 patients were examined with a diagnosis of RA (verified according to criteria ACR/EULAR 2010), without concomitant pathology. Among the examined patients with RA women predominated $168(86.6 \%)$, and there were 26 men (13.4\%). The age of patients was 22 to 65 years (mean age $47,7 \pm 10,22$ years), mean duration of the disease was $3,82 \pm 3,43$ years. Assessment of RA activity was done by DAS 28 index, using blood CRP in the formula. 152 patients were positive for the presence of anti-CCP ( $\geq 20 \mathrm{U} / \mathrm{ml})(78 \%)$ and $42(22 \%)$ - negative. Serum CRP concentrations (Vector-Best, Russia), anti-CCP (Orgentec, Germany), VEGF (BCM Diagnostic, Canada) were determined by ELISA. Statistical processing of the data was performed using non-parametric methods, univariate (ANOVA) variance analysis on a personal computer using a licensed software packages ("Microsoft-Excel" and "Statistica-Stat-Soft", USA)

Results: Analysis of VEGF level changes in the blood depending on the duration of $R A$ revealed that the measure was high in patients with small diseases duration 0-23 months $(472.96(341.1 ; 582.1) \mathrm{pg} / \mathrm{ml})$ compared with the group 5 years (324.1 $(199.2 ; 556.2) \mathrm{pg} / \mathrm{ml})(\mathrm{p}<0,04)$. Analysis of VEGF level in blood depending on the degree of RA activity showed that the VEGF concentration in blood increased with increasing degree of RA activity and it was the greatest - 564.4 $(340.1 ; 758.4) \mathrm{pg} / \mathrm{ml}$ in the group with a high degree (DAS28 >5.2) compared to the minimum (DAS28 $\leq 3,2)-230,5(178,1 ; 385,3) \mathrm{pg} / \mathrm{ml}$, and moderate (DAS28 $3,3-5,2)-356,4$ (278 9;553.1) pg/ml, ( $<<0,001 ; p=0,005$, respectively). Using ANOVA variance analysis, it was found that the degree of RA activity influenced the VEGF levels in the blood ( $K W=17,37 ; p<0,001)$.

Analysis of the VEGF levels in the blood depending on the level of anti-CCP 